\title{
Morningness-eveningness and emotion dysregulation incremental validity in predicting social anxiety dimensions
}

This article was published in the following Dove Press journal:

International Journal of General Medicine

6 September 2017

Number of times this article has been viewed

\author{
Esfandiar Azad-Marzabadi' \\ Sohrab Amiri² \\ 'Behavioral Sciences Research Center, \\ Baqiyatallah University of Medical \\ Sciences, Tehran, Iran, ${ }^{2}$ Faculty of \\ Literature and Humanities, Urmia \\ University, Urmia, Iran
}

\begin{abstract}
This study investigates the usefulness of morningness-eveningness and emotion dysregulation for better understanding of social anxiety dimensions. Specifically, associations between morningness-eveningness and incremental validity of emotion dysregulation as a predictor of social anxiety were examined. Data were obtained from a sample of normal students $(\mathrm{N}=510)$. Results of regression analyses showed that morningness was a significant predictor of social anxiety variables. Dimensions of emotion dysregulation had multiple associations with facets from social anxiety. Emotion dysregulation was found to be a positive predictor of social anxiety. The results expand the understanding of social anxiety and indicate how the domains of morningness-eveningness and emotion regulation could explain social anxiety in a normal population.
\end{abstract}

Keywords: emotion dysregulation, eveningness, morningness, social anxiety

\section{Introduction}

Social anxiety is an intense fear of negative evaluation by others in social situations, based on Diagnostic and Statistical Manual of Mental Disorders-5 (DSM-5). ${ }^{1}$ Its chronicity, ${ }^{2}$ prevalence, ${ }^{3}$ and personal and societal costs, ${ }^{4,5}$ as well as comorbidity with mental disorders, ${ }^{6}$ have been established.

Accordingly, social anxiety disorder has a significant effect on social, interpersonal, and educational functioning, and other aspects. ${ }^{7,8}$ Understanding the mechanisms affecting the development and persistence and intensifying of social anxiety plays an important role in developing effective intervention and in improvement of the disorder. One important factor that has received little attention in regard to anxiety disorder is the biologic dimensions of personality.

The morningness-eveningness (M-E) trait is known as biological dimension of personality, which is largely a result of heredity. ${ }^{9}$ Besides the physiological differences between M-E types, some psychological differences have been reported between these two types as well. For example, eveningness has shown higher scores in extraversion ${ }^{10,11}$ and novelty seeking. ${ }^{12-14}$ Circadian cycles are time swings in the physiological and behavioral functions that roughly show 24-hour cycle. In humans, this cycle is regulated by a biologic clock found in the suprachiasmatic nucleus of the hypothalamus that regulates the secretion of melatonin in the pineal gland. ${ }^{15}$ There are individual differences in sleep-wake cycles and circadian time, so that some people prefer to wake up early in the morning and go to bed early at night, while others prefer the opposite pattern. ${ }^{16}$ Furthermore, another important factor in relation to anxiety disorders and $\mathrm{M}-\mathrm{E}$ is emotion regulation. ${ }^{17}$
Correspondence: Sohrab Amiri Urmia University, Shahid Rajaee Street, 12 meter Aqil, Sajjad Alley 3, No. 18, Hamedan City, Hamedan Province, Iran Tel +989197928021

Fax +98 08I 4422244

Email Amirysohrab@yahoo.com 
Emotion regulation has been defined as processes through which emotions are evaluated, monitored, maintained, and modified. ${ }^{18}$ In another definition, emotion regulation determines when and how people experience and express emotions. ${ }^{19}$ Emotion regulation difficulties play an important role in many psychological disorders. ${ }^{20}$ As such, the aim of research in the field of emotion regulation is understanding trajectories of mental illness. ${ }^{21}$

There are individual differences in emotional abilities, including identifying and understanding own and others' emotions, and the causes and outcomes of different emotions, and in the strategies used to regulate emotions. ${ }^{22,23}$ Emotion dysregulation plays an important role in psychological disorders, for example, anxiety, depression, and personality disorders. The researchers sought to examine the relationships between emotion dysregulation and anxiety disorder.

The current study investigated the relationships between $\mathrm{M}-\mathrm{E}$, emotion dysregulation, and social anxiety. It was hypothesized that a positive correlation exists between emotion dysregulation and social anxiety. Although no study has investigated the association between $\mathrm{M}-\mathrm{E}$ and social anxiety, it is assumed that morningness is negatively associated with social anxiety. In addition the role of $\mathrm{M}-\mathrm{E}$ in social anxiety and emotion dysregulation play an important role in social anxiety.

\section{Subjects and methods Ethical provisions}

All procedures performed in studies involving human participants were in accordance with the ethical standards of the institutional and/or national research committee and with the 1964 Helsinki Declaration and its later amendments or comparable ethical standards. The institutional review boards of Baqiyatallah University approved this study. Written informed consent was obtained from all individual participants included in the study.

\section{Participants and procedure}

The study participants consisted of 510 students who were selected through multistage cluster sampling among the university students by using Cochran's sampling table. This study was conducted on the university students. Research planning was conducted at the university's Psychological Counseling Center. Using a multistage cluster sampling method, five colleges and research centers were selected and from each of them, 25 classes were selected and data were collected from students in these classes. Inclusion criteria were age 18 years or older and not having been diagnosed with a medical condi- tion to date. Participants with a psychotic disorder, problems with substance use, and other disorders were excluded. In order to determine the exclusion and inclusion criteria, a selfreporting sheet was used (Figure 1). After collecting data, people who did not meet the necessary criteria were excluded from the analysis process. Participants completed a series of questionnaires following an informed consent procedure and were provided with debriefing information on the purpose of the study and given a list of community counseling agencies at the end of the survey as well.

\section{Measures}

\section{Emotion Dysregulation Questionnaire}

The questionnaire consists of 36 items and six subscales that are scored based on the 5-point Likert scale. The subscales include: 1) awareness of emotional responses, 2) clarity of emotional responses, 3) nonacceptance of emotional responses, 4) access to effective emotion regulation strategies, 5) difficulties in goal-directed behaviors, and 6) difficulties in controlling impulses. The emotion dysregulation scale has a good internal consistency $(\alpha=0.93) .{ }^{24}$ Good psychometric properties for this scale have been reported in Iranian society. Also, the internal consistency coefficient of the entire scale was $\alpha=82$ in the present study.

\section{Morningness-Eveningness Questionnaire}

The Morningness-Eveningness Questionnaire is composed of 19 self-report items. Each item required the individuals to denote the degree to which they prefer definite morningness (or eveningness) activities. For example, "assuming adequate environmental conditions, how easy is it for you to get up in the morning?" (1, not at all easy; 2 , not very easy; 3 , fairly easy; 4 , very easy). ${ }^{25}$ This scale is continuous. Higher scores indicate the morningness tendencies and lower scores represent the eveningness tendencies. Good psychometric properties for this scale have been reported in Iranian society. Also, the internal consistency coefficient of the total scale was $\alpha=71$ in the present study.

\section{Social Interaction Anxiety Scale}

The Social Interaction Anxiety Scale includes 20 items and is rated from 0 to 4 . Items are one's representative reaction to social interaction. Total scores range between 0 and 80 , with higher scores representing higher social anxiety. ${ }^{26}$ The scale has been validated in Iranian society, and good psychometric properties have been reported for this scale. Also, the internal consistency coefficient of the entire scale was $\alpha=74$ in the present study. 


\section{Social Anxiety Questionnaire}

The Social Anxiety Questionnaire addresses self-endorsed feelings of anxiety. ${ }^{27}$ The response is based on a "yes" or "no". The scale has good internal consistency $(\alpha=0.78) .{ }^{27}$ Good psychometric properties for this scale have been reported in Iranian society. Also, the internal consistency coefficient of the entire scale was $\alpha=75$ in the present study.

\section{Data analysis strategy}

Given that all the scales (dependent and independent variables) were continuous, data were analyzed using SPSS version 22. Bivariate correlations via Pearson correlation coefficient were used to examine the correlations between $\mathrm{M}-\mathrm{E}$ and emotion dysregulation with social anxiety. Next, multiple linear regression analysis was performed to test the hypothesis that emotion dysregulation has a significant incremental beyond $\mathrm{M}-\mathrm{E}$ in predicting the social anxiety dimensions.

\section{Results \\ Descriptive statistics}

Of the total participants, 342 were undergraduate students (67.05\%) and 168 were masters students or higher (32.95\%); 367 were females $(71.96 \%)$ and 136 were males $(28.04 \%)$. The mean and standard deviation ages of the students were 20.12 and 1.87, respectively, in males, and 21.04 and 2.02, respectively, in females.

Bivariate correlations among the study variables are presented in Table 1. Skew and kurtosis were in conventional range $(-1 \text { to } 1)^{28}$ for all of the variables.
Bivariate correlations showed that morningness was significantly negatively associated with social anxiety (Table 1). The dimensions of emotion dysregulation included Nonacceptance, Goals, Impulse, Strategies, and Clarity were positively associated with social anxiety. Emotion dysregulation was significantly negatively associated with morningness.

Multiple hierarchical regression analyses were conducted to investigate the incremental validity of emotion dysregulation domains when predicting social anxiety (Table 2). M-E was entered in the first step of regressions, followed by the Difficulties in Emotion Regulation Scale (DERS). Together, M-E domains explained 5\% and $4 \%$ of the variance in social anxiety and social interaction anxiety, respectively. After adding together M-E and DERS domains, the incremental validity of DERS was obtained to be equal to $16 \%$ and $18 \%$. Overall, $\mathrm{M}-\mathrm{E}$ and DERS explained $21 \%$ and $22 \%$ of the variance in social anxiety and social interaction anxiety, respectively.

\section{Discussion}

As expected, social anxiety was positively related to emotion dysregulation. Social anxiety was also more strongly related to greater use of internal dysfunctional emotion regulation strategies. This suggests that general emotion dysregulation may play an important role in social anxiety symptoms.

These results showed individuals with frequent negative thoughts about social interaction are more likely to have social anxiety if they use negative emotion regulation strategies to negative feelings related to social anxiety, or dysfunctional emotion regulation ways such as Goal-directed behaviors, Nonacceptance, Clarity, and other-blame generally. These

Table I Bivariate correlations for the study variables

\begin{tabular}{|c|c|c|c|c|c|c|c|c|c|c|}
\hline Variables & SAQ & SIAS & M-E & DERS & NonAcpt & Goals & Impulse & Awareness & Strategies & Clarity \\
\hline SAQ & I & & & & & & & & & \\
\hline SIAS & $0.57 * *$ & I & & & & & & & & \\
\hline M-E & $-0.21 * *$ & $-0.18^{* *}$ & I & & & & & & & \\
\hline DERS & $0.42 * *$ & $0.44 * *$ & $-0.13^{* *}$ & I & & & & & & \\
\hline NonAcpt & $0.37 * *$ & $0.37^{* *}$ & $-0.13^{* *}$ & $0.80 * * *$ & I & & & & & \\
\hline Goals & $0.28 * *$ & $0.32 * *$ & -0.03 & $0.73 * *$ & $0.50 * *$ & I & & & & \\
\hline Impulse & $0.35^{* *}$ & $0.34 * *$ & $-0.11 *$ & $0.83 * *$ & $0.63 * *$ & $0.63^{* *}$ & I & & & \\
\hline Awareness & -0.08 & -0.05 & 0.04 & 0.02 & $-0.20 * *$ & $-0.25 * *$ & $-0.18^{* *}$ & $\mathrm{I}$ & & \\
\hline Strategies & $0.44^{* *}$ & $0.45^{* *}$ & $-0.14^{* *}$ & $0.85^{* *}$ & $0.64^{* *}$ & $0.62 * *$ & $0.68 * *$ & $-0.20 * *$ & I & \\
\hline Clarity & $0.2 I^{* *}$ & $0.24 * *$ & $-0.12^{* *}$ & $0.59 * *$ & $0.39 * *$ & $0.23 * *$ & $0.35^{* *}$ & $0.22 * *$ & $0.33 * *$ & I \\
\hline Mean & 9.55 & 49.01 & 50.19 & 91.29 & 13.52 & 14.49 & 14.34 & 17.76 & 18.76 & 12.39 \\
\hline SD & 2.18 & 13.79 & 6.71 & 19.01 & 5.39 & 4.42 & 4.92 & 3.96 & 6.28 & 3.33 \\
\hline Minimum & 7 & 20 & 29 & 50 & 6 & 5 & 6 & 7 & 8 & 5 \\
\hline Maximum & 14 & 92 & 67 & 143 & 50 & 25 & 30 & 30 & 40 & 24 \\
\hline Skew & 0.40 & 0.11 & -0.27 & 0.10 & 0.97 & 0.22 & 0.55 & 0.24 & 0.35 & 0.04 \\
\hline Kurtosis & -0.98 & -0.37 & -0.10 & -0.54 & 0.19 & -0.39 & 0.11 & 0.05 & -0.55 & -0.09 \\
\hline
\end{tabular}

Note: $* P<0.05, * * P<0.01$.

Abbreviations: DERS, Difficulties in Emotion Regulation Scale; M-E, morningness-eveningness; NonAcpt, nonacceptance; SAQ, Social Anxiety Questionnaire; SD, standard deviation; SIAS, Social Interaction Anxiety Scale. 
Table 2 Multiple linear hierarchical regression analyses

\begin{tabular}{|c|c|c|c|c|c|c|c|c|}
\hline \multirow[t]{2}{*}{ Predictor } & \multicolumn{4}{|l|}{ SAQ } & \multicolumn{4}{|l|}{ SIAS } \\
\hline & $F(I, 508)$ & $\Delta \boldsymbol{R}^{2}$ & Step I $\beta$ & Step $2 \beta$ & $F(1,508)$ & $\Delta \boldsymbol{R}^{2}$ & Step I $\beta$ & Step $2 \beta$ \\
\hline Step I M-E & $24.94 * * *$ & $0.5^{* * *}$ & $-0.21^{* * *}$ & $-0.16 * * *$ & $17.23 * * *$ & $0.4^{* * *}$ & $-0.18 * * *$ & $-0.13 * * *$ \\
\hline Predictor & $F(I, 507)$ & $\Delta \boldsymbol{R}^{2}$ & Step I $\beta$ & Step $2 \beta$ & $F(1,507)$ & $\Delta R^{2}$ & Step I $\beta$ & Step $2 \beta$ \\
\hline Step 2 DERS & $101.01 * * *$ & $0.16 * * *$ & & $0.40 * * *$ & $115.92 * * *$ & $0.18^{* * *}$ & & $0.43 * * *$ \\
\hline
\end{tabular}

Notes: Standardized regression coefficients $(\beta)$ are reported. $* * * P<0.001$.

Abbreviations: DERS, Difficulties in Emotion Regulation Scale; M-E, morningness-eveningness; SAQ, Social Anxiety Questionnaire; SIAS, Social Interaction Anxiety Scale.

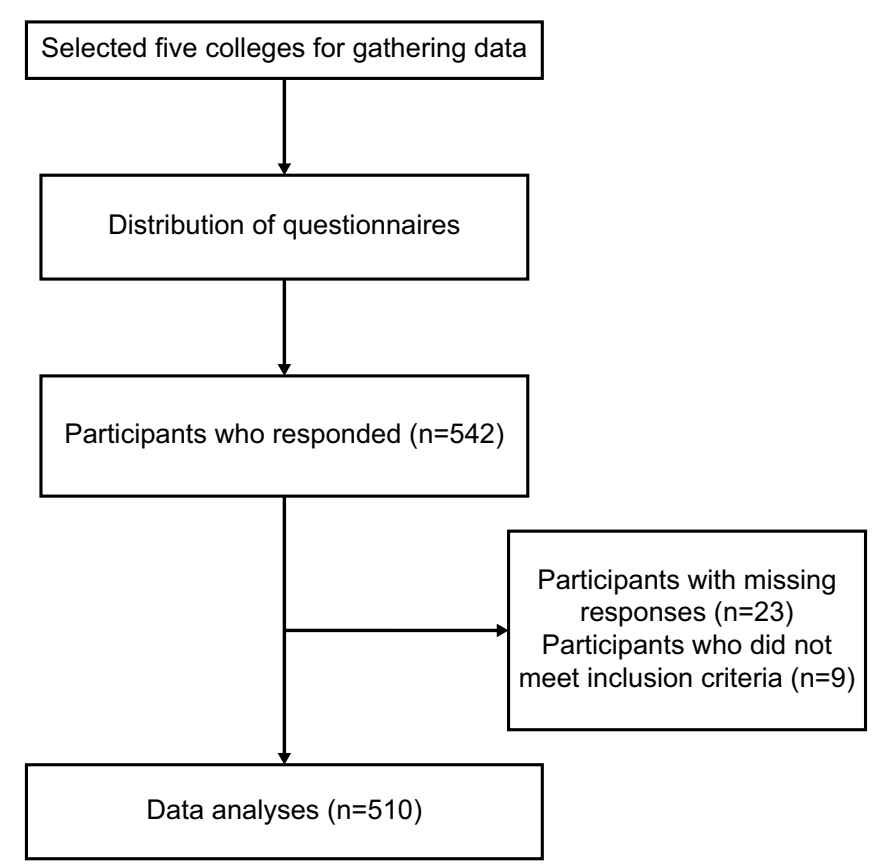

Figure I Flowchart of the study.

findings confirm previous research findings that report correlations between negative emotion regulation and psychological symptoms. ${ }^{29}$

The M-E trait was significantly associated with social interaction anxiety and social anxiety. These findings show the role of morningness in psychological disorders. The current study is the first to investigate the differential relationships of $\mathrm{M}-\mathrm{E}$ trait with social interaction anxiety and social anxiety.

One of the main goals of our study was to investigate the incremental validity of emotion dysregulation in predicting social anxiety in addition to the $\mathrm{M}-\mathrm{E}$ trait aspects. Accordingly, results supported the hypothesis that emotion dysregulation has high incremental validity in predicting social anxiety.

The investigation of factors associated with social anxiety is an important research field. Although some attempts have been made to address biological factors related to social anxiety, the impact of such factors is limited and it is improbable that all factors of social anxiety are completely eradicated. Improving emotion regulation may be helpful to reduce anxiety.

These findings can have an important role in the conceptualization of social anxiety disorder. In addition, the relationship between eveningness and social anxiety may be due to using negative emotion regulation to scope social anxiety in eveningness types.

There are some limitations in the study. First, data were self-reported. The recall bias likely impacted self-reporting. Additionally, the current sample is normal. The present study is the first study to investigate the associations between the M-E trait, emotion dysregulation, and social anxiety. In conclusion, this study provides empirical support for the role of biological dimension of personality and emotion dysregulation in social anxiety.

\section{Disclosure}

The authors report no conflicts of interest in this work. 


\section{References}

1. American Psychiatric Association. Diagnostic and Statistical Manual of Mental Disorders. 5th ed. Washington, DC: American Psychiatric Association; 2013.

2. Bruce SE, Yonkers KA, Otto MW, et al. Influence of psychiatric comorbidity on recovery and recurrence in generalized anxiety disorder, social phobia, and panic disorder: A 12-year prospective study. Am J Psychiatry. 2005;162(6):1179-1187.

3. Kessler RC, Berglund P, Demler O, Jin R, Merikangas KR, Walters EE. Lifetime prevalence and age-of-onset distributions of DSM-IV disorders in the National Comorbidity Survey Replication. Arch Gen Psychiatry. 2005;62(6):593-602.

4. Acarturk C, de Graaf R, van Straten A, Have MT, Cuijpers P. Social phobia andnumber of social fears, and their association with comorbidity, health-related quality of life and help seeking: a population-based study. Social Psychiatry Psychiatr Epidemiol. 2008;43(4):273-279.

5. Rodebaugh TL. Social phobia and perceived friendship quality. J Anxiety Disord. 2009;23(7):872-878.

6. Magee WJ, Eaton WW, Wittchen HU, McGonagle KA, Kessler RC. Agoraphobia, simple phobia, and social phobia in the National Comorbidity Survey. Arch Gen Psychiatry. 1996;53(2):159-168.

7. Kessler RC. The impairments caused by social phobia in the general population: implications for intervention. Acta Psychiatr Scand Suppl. 2003;417:19-27.

8. Wittchen E, Fuetsch M, Sonntag H, Muller N, Liebowitz M. Disability and quality of life in pure and comorbid social phobia. Findings from a controlled study. Eur Psychiatry. 2000;15(1):46-58.

9. Adan A, Archer SN, Hidalgo MP, Di Milia L, Natale V, Randler C. Circadian typology: a comprehensive review. Chronobiol Int. 2012;29(9): 1153-1175.

10. Díaz-Morales JF. Morning and evening-types: exploring their personality styles. Pers Individ Diff. 2007;43(4):769-778.

11. Matthews G. Morningness-eveningness as a dimension of Personality: trait, state and psychophysiological correlates. Eur J Personal. 1988;2(4): 277-293.

12. Caci H, Robert P, Boyer P. Novelty seekers and impulsive subjects are low in morningness. Eur Psychiatry. 2004;19(2):79-84.

13. Killgore WD.Effects of sleep-deprivation and morningness-eveningness traits on risk-taking. Psychol Rep. 2007;100(2):613-626.

14. Maestripieri D. Night owl women are similar to men in their relationship orientation, risk-taking propensities, and cortisol levels: Implications for the adaptive significance and evolution of eveningness. Evol Psychol. 2014;12(1):130-147.
15. Piffer D, Ponzi D, Sapienza P, Zingales L, Maestripieri D. Morningnesseveningness and intelligence among high-achieving US students: night owls have higher GMAT scores than early morning types in a top-ranked MBA program. Intelligence. 2014;47:107-112.

16. Adan A, Archer SN, Hidalgo MP, Di Milia L, Natale V, Randler C. Circadian typology: a comprehensive review. ChronobiolInt. 2012;29(9): 1153-1175.

17. Pace-Schott EF, Rubin ZS, Tracy LE, Spencer RM, Orr SP, Verga PW. Emotional trait and memory associates of sleep timing and quality. Psychiatry Res. 2015;229(3):999-1010.

18. Thompson RA. Emotion regulation: a theme in search of definition. Monogr Soc Res Child Dev. 1994;59(2-3):25-52

19. Gross JJ. Antecedent-and response-focused emotion regulation: divergent consequences for experience, expression, and physiology. $J$ Pers Soc Psychol. 1998;74(1):224-237.

20. Gross JJ, Levenson RW. Hiding feelings: the acute effects of inhibiting negative and positive emotion. J Abnorm Psychol. 1997;106(1):95-103.

21. Amstadter A. Emotion regulation and anxiety disorders. J Anxiety Disord. 2008;22(2):211-221.

22. Cummings EM. Coping with background anger in early childhood. Child Dev. 1987;58(4):976-984.

23. Denham SA. Emotional Development in Young Children. New York: Guilford Press; 1998.

24. Gratz KL, Roemer L. Multidimensional assessment of emotionregulation and dysregulation: development, factor structure, and initial validation of the difficulties in emotion regulation scale. J Psychopathol Behav Assess. 2004;26(1):41-54.

25. Horn JA, Ostenberg O. A self-assessment questionnaire to determine morningness-eveningness in human circadian rhythms. Int J Chronobiol. 1976;4(2):97-110.

26. Brown EJ, Turovsky J, Heimberg RG,Juster HR, Brown TA, Barlow DH Validation of the social interaction anxiety scale and the social phobia scale across the anxiety disorders. Psychol Assessment. 1997;9(1):21-27.

27. Rudy BM. Socially oriented negative self-referent cognition in youth: the development and validation of a measure [dissertation]. Shreveport, LA: Louisiana State University; 2013. Available from: digitalcommons. 1su.edu/gradschool_dissertations/644/. Accessed June 1, 2017.

28. George D, Mallery P. SPSS for Windows Step by Step:A Simple Guide and Reference (11.0 update) 4th ed. Boston, MA: Allyn\& Bacon; 2003.

29. Betts J, Gullone E, Allen JS. An examination of emotion regulation, temperament, and parenting style as potential predictors of adolescent depression risk status: a correlational study. Brit J Dev Psychol. 2009;27(2):473-485.
International Journal of General Medicine

\section{Publish your work in this journal}

The International Journal of General Medicine is an international, peer-reviewed open-access journal that focuses on general and internal medicine, pathogenesis, epidemiology, diagnosis, monitoring and treatment protocols. The journal is characterized by the rapid reporting of reviews, original research and clinical studies across all disease areas.

\section{Dovepress}

The manuscript management system is completely online and includes a very quick and fair peer-review system, which is all easy to use. Visit http://www.dovepress.com/testimonials.php to read real quotes from published authors. 